\title{
LIQUIDITY RISK PREMIA: AN EMPIRICAL ANALYSIS OF EUROPEAN CORPORATE BOND YIELDS
}

\author{
Raquel M. Gaspar \\ Advance Research Center, ISEG, Technical University of Lisbon \\ Patricia Pereira \\ Sociedade Gestora dos Fundos de Pensões do Banco de Portugal
}

\begin{abstract}
In this study we highlight the importance of liquidity risk, especially in periods of market stress, and advocate in favour of an explicit consideration of a liquidity premium when using mark-to-model methodologies to value financial assets.

For European corporate bonds, we show that the liquidity premium, calculated as the difference between the yield spread of corporate bonds and the spread of credit default swaps, grew significantly during the recent market turmoil not only in absolute terms but also in relative terms. Although liquidity premiums were far from stable during the time frame of analysis - from 1 January 2005 to 31 December 2009 - on average roughly $40 \%$ of corporate yield spreads can be interpreted in terms of liquidity premia.

We propose direct matching between the CDS and the underlying reference assets when computing liquidity premia. This differs from what seems to be the industry standard, which is simply to use indices when trying to infer market implied liquidity premia. Although computationally more demanding, the method we use is sounder from a theoretical point of view and produces richer results and analysis. With this method we are able present an analysis of liquidity risk premia per sector of activity.
\end{abstract}

Keywords: Liquidity Premium, Credit Risk, Yield Corporate Spread, CDS Spread.

JEL Classification: E3, E40, G12, G18

Correspondence Address: Advance Research Center, ISEG, Technical University of Lisbon, Rua Miguel Lupi 20, 1249-078 Lisboa, Portugal. E-mail: Rmgaspar@iseg.utl.pt.

Financial support of FCT under grant UTAustin/MAT/0057/2008 is gratefully acknowledged. 


\section{INTRODUCTION}

The recent financial crisis, whose origins lie in the North American subprime credit markets, gave rise to an unprecedented situation in which markets found themselves with no liquidity, and this led to a series of events that shook the world economy. Several major US financial institutions went bankrupt while others were bailed out by the US government because their cash flow was unable to meet their short term commitments and/or because their capital was insufficient to fill their mid and long term obligations. This situation sparked debate on the accuracy of asset valuation as determined by the accounting norms set by the International Accounting Standards Board (IASB) or the Financial Accounting Standards Board (FASB), since during the crisis, using transaction prices as the basis for valuation criteria for fair value significantly underestimated the illiquid financial instruments and, as a result, the companies' equity.

In view of this situation, the IASB and FASB proposed that some classes of assets be reclassified in accounts, and they recommended that mark-to-model valuation methodologies be used to determine the fair value of financial instruments that are not considered tradable on a stock market. The recommendation would apply to securities that do not show current quotes, transactions showing significant trading volume and securities whose prices had fluctuated significantly in absence of any forced trading. The methodologies and different valuation techniques should include as much relevant available information as possible, and they should seek to reflect current market conditions, including any necessary adjustments to risk, particularly credit risk and liquidity risk. This requires regular calibration of the variables. In recent years the most common method for valuation used by financial institutions and security fund managers has been discounted cash-flow analysis. In this method the future estimated cash flows of financial instruments are discounted at a certain discount rate, taking into account the maturity of the future cash flows and reflecting the associated risks, such as credit risk and liquidity risk. This discount rate is usually determined by the future rate of return, i.e. the yield, on liquid assets with similar characteristics whenever market prices for these are available. Otherwise, discount rates are computed adding a credit spread to the risk free rate.

In this paper we study liquidity risk, and we shall show that liquidity risk is an important component of corporate bond yields. Further, we shall argue that discount rates used in mark-to-model valuation of illiquid financial assets should include a liquidity risk premium. This is particularly so during periods of stressed markets, such as the recent financial crisis, since liquidity risk reflects the losses incurred in the costs of settling financial instruments.

\section{LIQUIDITY RISK IN CORPORATE YIELDS}

Liquidity risk for an investor or company can be analyzed in two perspectives, which are interconnected especially when financial markets are stressed. The first, 132 
known as market liquidity risk, arises from the potential risks of loss associated with the sale of assets, particularly when it is not possible to liquidate a position without significantly affecting the market price. The second, cash-flow liquidity risk, stems from the latent need to obtain funds within a short time span in order to meet immediate contractual payment obligations. This study focuses only on the first perspective and any references to liquidity risk hereafter refer to market liquidity risk.

Liquidity risk, especially the liquidity premium inherent in corporate bond yields, has been the object of several studies, and interest in the theme has grown in the aftermath of the recent financial crisis. Empirical studies that seek to quantify the liquidity premium in corporate bond yields do not always arrive at similar results, but there is consensus that a liquidity premium exists and that it varies over time, reaching significant values when there are extreme events. Most studies can be classified according to their methodology as follows: (i) matching methods, e.g. Dignan (2003) and Longstaff et al. (2005); (ii) methodologies based on structural models, e.g. Collin-Dufresne and Goldstein (2001) and Ericsson et al. (2005); or (iii) methodologies based on econometric models, e.g. De Jong and Driessen (2005) and Chen et al. (2007).

The first group of studies computes the liquidity premium by means of comparing either the yields of bonds that have the same characteristics, except for liquidity, as in Dignan (2003) or by comparing credit default swap (CDS) spreads with yield spreads of the underlying corporate bonds as in Longstaff et al. (2005). These matching methods are based upon the sound theoretical notion of no arbitrage, but require that the objects being matched are indeed similar in all aspects other than liquidity, which is not always easy to achieve.

The methodologies based on structural models compare the yield on illiquid bonds with the cost of a synthetic liquid position with otherwise equivalent risk characteristics constructed from risk-free bonds and a call option on the assets from the insurer, as presented, for example, in Weber (2007). Given that these options are not tradable, the value is computed on the basis of the Merton (1974) model and its subsequent modifications, all of which assume that the company assets follow a geometric Brownian movement. Modifications by Collin-Dufresne and Goldstein (2001) have enabled debt values to be adjusted in response to changes in company value, thus reducing the sensitivity of the credit spreads to the company's value. Later Cremers et al. (2004) incorporated the implicit volatility of the options on company equity, and Ericsson et al. (2005) showed that structural models' underestimation of corporate bond spreads may not be directly related to the inability to measure default risk correctly, but rather to the existence of other factors such as liquidity risk. Despite their intuitive theoretical appeal, structural models require a large set of unobservable parameters. This often leads to the use of subjective values for key parameters, such as the volatility of company assets or its debt maturity.

By contrast, econometric models such as those by Chen et al. (2007), Bao et al. (2009) and Dick-Nielsen et al. (2009) use liquidity measures as explanatory variables for bond yields. The liquidity measures, initially developed by Roll (1984), Kyle (1985) 
and Amidhud et al. (1986), are underpinned by information available on prices, namely the difference between the sell and buy price (the bid-ask spread) and the number of assets traded. Most studies of this kind aim to analyse the sources of illiquidity in the market, and they seek to understand the influence of transaction mechanisms on security prices. The most recent studies conclude that the liquidity premium increases with higher maturities and downgrading of the credit rating. See, for instance De Jong and Driessent (2005), Houweling et al. (2005), Bao et al. (2009), and Dick-Nielsen et al. (2009). The main limitation of this methodology lies in the fact that many econometric models are regression models in which it is difficult to capture systematically the non linear dependencies in distribution tails which are often observed in stressed markets.

In this study we will use a matching method proposed by Longstaff et al. (2005), and compare CDS spreads with yield spreads of the underlying reference corporate bonds. Besides being based on sound theoretical no arbitrage grounds, this method has the additional advantage of relying on data that are directly observable or implied from market quotes. Yield spreads are nothing but the difference between yields of corporate bonds and yields of otherwise similar bonds with no default risk. Theoretically, in frictionless (liquid) markets, there should be a direct correspondence between yield spreads and CDS spreads, since, in that case, both spreads reflect only the credit risk of the reference entity (Duffie, 1999). Nonetheless, several studies have found a difference between the two spreads, which became known as "negative basis". Longstraff et al. (2005) explain the existence of a negative basis by the difference in the liquidity of the two types of products. CDS contracts are typically very liquid over-the-counter (OTC) derivative contracts, while the market for the underlying corporate bonds is, in many cases, relatively dry. So, they assume CDS spreads reflect only credit risk of the reference bond issuer while bond yield spreads reflect not only credit risk but also liquidity risk, and they equate the liquidity premium with the corresponding value of the negative basis. This is the liquidity premium measurement we will adopt in this study. An important limitation of the proposed measure is the fact it assumes CDS spreads reflect nothing but the credit risk of the underlying reference entity. To the extent CDS spreads may inherently include other risks, the method leads to biased results and underestimation of liquidity risk. For recent studies supporting the idea CDS spreads include risks other than credit risk of the reference entity see, for instance, Duffie and Liou (2001), Chen et al. (2005), Tang and Yan (2006), or Bongaerts et al. (2008). These and other authors have rightly drawn attention to the fact that CDS spreads may include, at least, the insurer's counterparty risk, liquidity risk stemming not from the underlying reference assets but from their systemic nature and/or uncertainty associated with the way CDS markets operate, in particular settlement risk. Counterparty risk results from the OTC nature of CDS contracts and is the risk that the counterparty in the CDS contract will not meet its obligations (thus, credit risk of the counterparty entity and not of reference entity). Systemic liquidity risk reflects the overall market uncertainty, especially in periods of market stress, that lead to difficulties in finding counterparties to enter a CDS contract. Finally settlement risk 134 
has to do with the uncertainty about the consequences of the requirement of physical delivery of the reference bonds (for CDS with physical delivery clauses), upon default of the reference entity. During the recent crisis many of these other risks of CDS contracts became more or less evident and led to important changes in the functioning of European CDS markets. In September 2008 the bankruptcy of Lehman Brothers led to serious problems in the insurance undertaking, AIG, who had entered CDS contracts selling (in huge amounts) protection against a possible default by Lehman Brothers. When Lehman Brother defaulted, AIG was able to remain solvent only because of US government financial intervention and support; otherwise it would have defaulted in all its CDS contracts. This and many other less noticeable cases made market participants worry seriously about counterparty risk. Also, by the time Lehman Brothers defaulted, the nominal values associated with CDS contracts written on their debt were much bigger than the nominal values of the whole of their debt, showing clearly that physical settlement of all CDS contracts would be impossible. In Europe the aftermath of the recent crisis saw the establishment of Central Counterparties Clearing Houses, whose aim is to provide efficiency, transparency and stability to financial markets, especially to OTC derivative markets. These organizations have significantly mitigated the counterparty and settlement risks inherent in CDS contracts by the establishment of the margin account system and auctions to help financially settle CDS contracts. CDS contracts are by now, once again, among the most liquid traded derivatives.

With the new CDS market functioning rules, CDS spreads are now more than ever a good proxy for the credit risk of the issuer of the underlying reference bond. It is, therefore, our opinion that the use of matching methods, if possibly not appropriate in the past, will provide good estimates of liquidity premia from now on.

Nonetheless, we do acknowledge, this may have not been so during the period of our empirical analysis and our results may be biased. We stress, however, that if CDS spreads included other risks than the credit risk of the reference entity, then by using the Longstaff et al. (2005) measure we will be underestimating liquidity risk premia, and this actually makes our findings and conclusions all the more sounder.

\section{EMPIRICAL ANALYSIS OF LIQUIDITY RISK}

The universe of our empirical analysis is all entities that belong to the 5 -year Markit iTraxx Europe CDS index, between 1 January 2005 and 31 December 2009, and their respective reference corporate bonds. This index is based upon the $125 \mathrm{CDS}$ contracts most frequently traded in the previous six months referencing European investment grade companies -25 from the financial sector, 20 from the telecommunications, media and technology sector (TMT), 20 from the industrial sector, 20 from the energetic sector, 30 from the consumer sector, and 10 from the automotive sector (auto manufacturers) - and it is updated biannually, in March and September, which gives rise to new index "series". Eleven index series (series number 2 - 11 inclusive) fall within the time span of our study referring to a total of 180 different entities. 


\subsection{METHOD IMPLEMENTATION ISSUES AND DATA}

The non arbitrage argument underlying the measurement of liquidity premium as proposed by Longstaff et al. (2005) requires the CDS spreads to be compared with the yield spreads of the underlying bonds. In accordance with this, we selected from the original set of 180 entities only the entities whose CDSs and respective reference European bonds had historical information (mid prices of the CDS and yield-to-maturity mid of the reference bonds) that was available and reliable over the 1,304 daily observations of the period under study. This filtering process reduced the number of entities under analysis to 54: 12 financial, 12 energetic, 10 industrial, 9 TMT, 8 consumer, and 3 auto manufacturers. Despite the significant reduction in the number of entities, it is important to note that one reason explaining absence of bond related reliable information is absence of liquidity itself. Thus, by considering only bonds available and reliable information, we will be (once again) underestimating the true liquidity risk premia in the market. As before, this second bias we introduce in the empirical analysis, also reinforces our main conclusions about the importance liquidity risk premia has on corporate bond yield spreads.

It should also be noted that by using a direct matching between CDS contracts and their underlying bonds, we can (by definition) achieve a correspondence between the entities underlying both products, but we cannot guarantee correspondence between the maturity of the CDS contract and that of the underlying bond. They are not necessarily the same, even though they are usually close.

An alternative to the exact matching between CDS and the underlying bonds that seems popular in the industry consists of computing the difference between an average CDS spread and a spread associated with the average yield of a bond index. While this method is simple as the market information is readily available in CDS indices and bond indices, it is questionable from a theoretical point of view because the notion of non arbitrage cannot be applied in aggregate terms (not to mention one should not average spreads or yields). Moreover, it is limited by the fact that it is seldom possible to establish a correspondence between the two indices with regard to the entities or the maturity of the underlying products. Nevertheless, in view of its popularity and simplicity, we shall use it later to test the robustness of the results that were obtained by the matching method, which we consider to be theoretically sounder. For this purpose we compute an average yield spread (see more details bellow) from information gathered on the Markit iBoxx Euro Corporates 3-5 and Markit iBoxx Euro Corporates 5-7 indices and compared it with the average 5-year Markit iTraxx Europe CDS spread.

Finally, in order to compute the liquidity premium it became necessary to determine the individual yield spread of each reference bond, which for ease of exposition we will simply refer to as corporate spread. We used information on the Euro Benchmarks curve as a proxy for risk-free bond yields for this purpose. Euro Benchmarks is made up exclusively of German and French treasury bonds, and we matched the maturities of the yields of the Euro Benchmarks with those of the corporate bonds by means of linear interpolation. When computing the corporate spreads, some, albeit few, 136 
unreliable observations were noted. We attribute this to the linear interpolation of the risk-free yields. Whenever in comparison with the previous day and the following day a bond registered an absolute daily change that was greater than $20 \%$ of the average daily absolute change in the spreads of other bonds, the value was replaced by the first valid observation determined on the immediately preceding day. Furthermore, to check that our results were not being influenced by the proxy for the risk-free bond yield, the 5-year swap rates were used in the tests for robustness.

All market data were obtained from the Bloomberg financial terminal.

\subsection{RESULTS AND MAIN FINDINGS}

In the following we present results in terms of both absolute and liquidity risk premia as defined by the following formulae

$$
\begin{aligned}
& \text { Absolute Liquidity Risk Premium }=\text { Corporate spread }- \text { CDS spread } \\
& \text { Relative Liquidity Risk Premium }=\frac{\text { Corporate spread }-C D S \text { spread }}{\text { Corporate spread }} .
\end{aligned}
$$

The absolute liquidity risk premium gives us the difference one should consider in discount rates of illiquid versus liquid instruments. The relative liquidity risk is the ratio of the absolute liquidity premium to the total corporate spread tells us how much of corporate spreads are due to liquidity risk.

Figure 1

Evolution of Liquidity Premium between 01.01.2005 and 31.12.2009

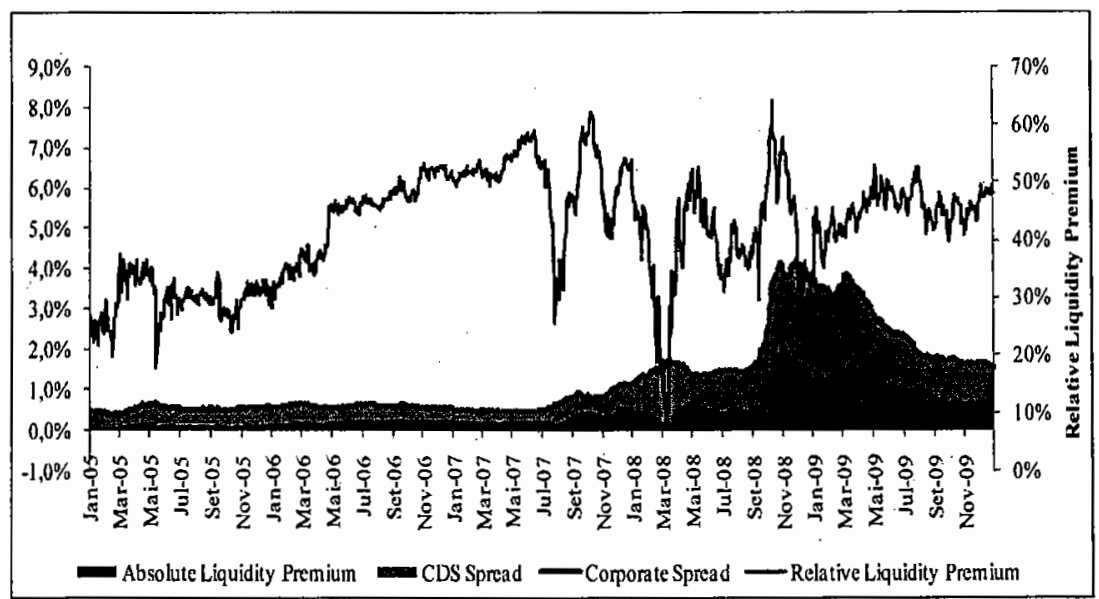

Figure 1 shows the evolution of average absolute liquidity premia, CDS spreads and corporate spreads for the period under study: The dark blue line represents the relative liquidity premium. Analysis of the evolution of the indicators between 1 January 2005 and 31 December 2009 reveals 4 sub-periods. In an initial sub-period that lasts 
until mid August 2007, the absolute liquidity premium remained stable and relatively low at around 22 basis points, with similarly low corporate spreads and CDS spreads. This was due to a favourable macroeconomic environment that was underpinned by economic growth in emerging economies, significant gains in the financial markets and low interest rates. Over this period the relative liquidity premium gradually increased from approximately $25 \%$ to a high of $59 \%$ in June 2007 , after which it dropped significantly to approximately $30 \%$ in July 2007 . The fall was due to an increase in CDS spreads following rumours of high losses in hedge funds that had invested in derivatives and structured products based on subprime mortgages in addition to rumours that led ratings agencies to downgrade the ratings of several entities and bond issues, given growing doubts about the rigour and valuation criteria used. In a second sub-period, between the second half of August 2007 and the end of August 2008, the absolute liquidity premium recovered slowly but steadily, with corporate spreads rising more than CDS spreads. This trend was broken only temporarily in March 2008 in the wake of the Bear Stearns' bankruptcy, when CDS spreads shot up to levels never seen before. Until then Bear Sterns had been one of the major sellers of CDS, and following their bankruptcy the liquidity premium in relative terms fell to its lowest value, $8.3 \%$, for the whole period under analysis. The third sub-period, lasting from the beginning of the last quarter in 2008 to the end of March 2009, coincides with the climax of the financial crisis. Initially between mid September 2008 and the beginning of November 2008 the absolute liquidity premium rose sharply, around $1.5 \%$, reaching a high of $2.33 \%$. During this period the weight of the liquidity premium also reached its highest point over the five years, $64.1 \%$. This situation was brought about by the bankruptcy of several major North American financial institutions, such as Lehman Brothers, and the hardship encountered by other companies such as AIG and General Motors, both of whom were bailed out by the Federal Reserve, which in turn led to a substantial rise in interbank market spreads and corporate spreads. After declining to around $1.25 \%$

Table 1

Descriptive Statistics: Liquidity Premium

\begin{tabular}{lrrrr}
\hline Descriptive Statis tics & $\begin{array}{c}\text { Corporate } \\
\text { Spread }\end{array}$ & $\begin{array}{c}\text { CDS } \\
\text { Spread }\end{array}$ & $\begin{array}{l}\text { Absolute } \\
\text { Liquidity } \\
\text { Premium }\end{array}$ & $\begin{array}{l}\text { Relative } \\
\text { Liquidity } \\
\text { Premium }\end{array}$ \\
\hline Mean & $1,26 \%$ & $0,72 \%$ & $0,54 \%$ & $42,0 \%$ \\
Standard Error & $0,03 \%$ & $0,02 \%$ & $0,01 \%$ & $0,3 \%$ \\
Median & $0,64 \%$ & $0,40 \%$ & $0,29 \%$ & $44,5 \%$ \\
Standard Deviation & $1,02 \%$ & $0,58 \%$ & $0,47 \%$ & $9,6 \%$ \\
Variance & $0,01 \%$ & $0,00 \%$ & $0,00 \%$ & $0,9 \%$ \\
Kurtosis & 0,97 & 1,58 & 1,75 & $-0,38$ \\
Skewness & 1,43 & 1,52 & 1,55 & $-0,44$ \\
Minimum & $0,37 \%$ & $0,19 \%$ & $0,07 \%$ & $8,3 \%$ \\
Maximum & $4,22 \%$ & $2,75 \%$ & $2,33 \%$ & $64,1 \%$ \\
Sum & 16 & 9 & 7 & 547 \\
Count & 1,304 & 1.304 & 1,304 & 1.304 \\
Confidence Interval $(95,0 \%)$ & $0,06 \%$ & $0,03 \%$ & $0,03 \%$ & $0,5 \%$ \\
\hline
\end{tabular}

138 
in December 2008, which was due to a temporary rise in CDS spreads, the absolute liquidity premium remained at approximately $1.50 \%$ to the end of the first quarter of 2009. In relative terms the liquidity premium fluctuated between $35.0 \%$ and $45.0 \%$. April 2009 marks the beginning of a fourth period in which stabilization of the financial markets led to a decline in corporate spreads and CDS spreads. The absolute liquidity premium similarly showed a gradual decining trend, and it stood at around $0.75 \%$ on 31 December 2009. In relative terms it continued to fluctuate between $40.0 \%$ and $50.0 \%$ during this final period. On 31 December 2009 it stood at $48.2 \%$ of the yield spread.

Table 1 and Figure 2 show complementary statistical information with regard to the averages of corporate spreads, CDS spreads, absolute liquidity premium and relative liquidity premium. The first three variables exhibit a mean that is above the median, indicating positive skewness, which is confirmed by the skewness coefficient.

Figure 2

Histograms of the average (a) CDS spread, (b) corporate spread, (c) absolute liquidity premium and (d) relative liquidity premium
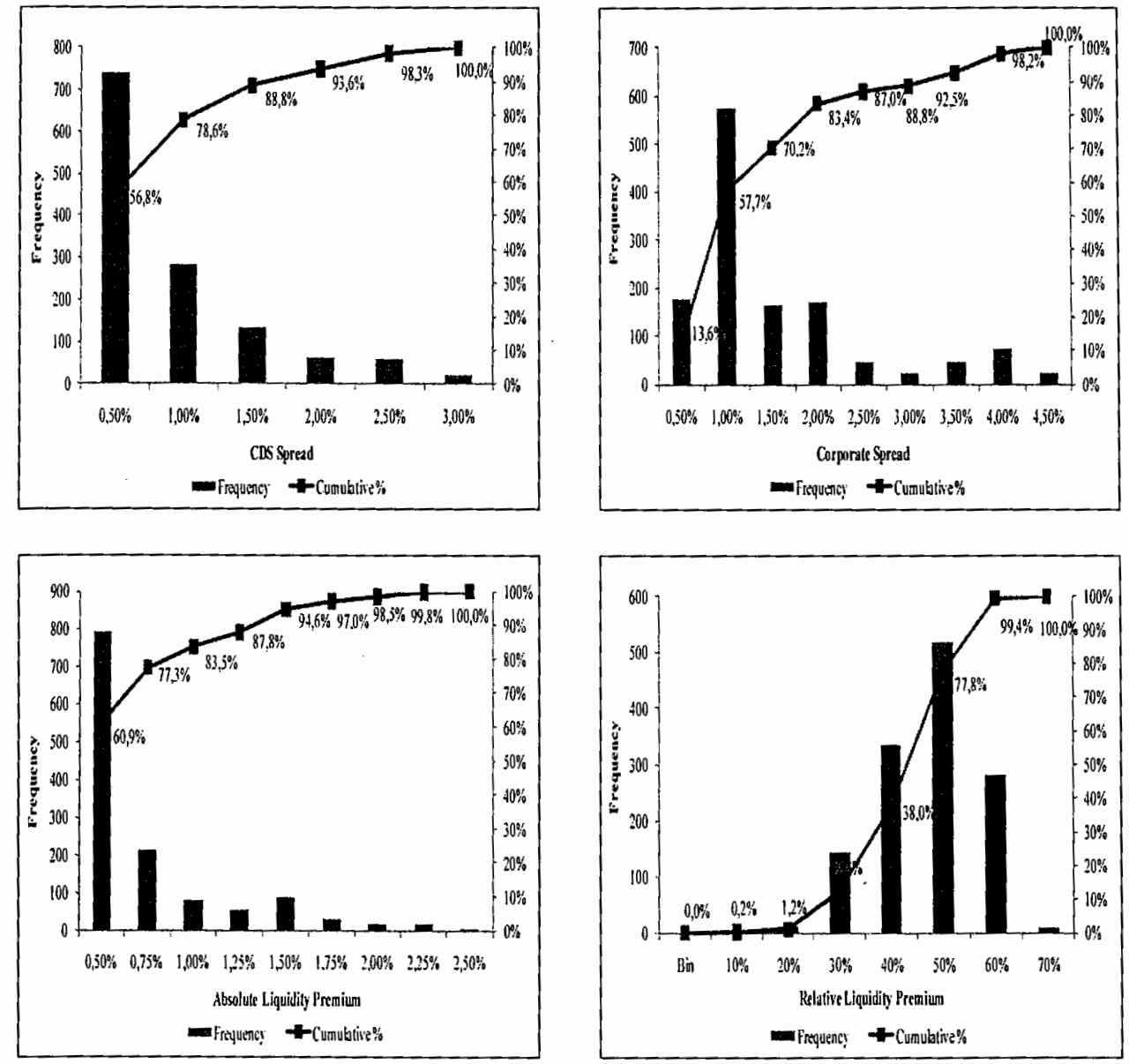
The kurtosis indicator, at less than 3 in all three cases, shows platykurtic distributions. The mean-standard deviation and variance indicators reveal a significant concentration in the distributions, which is due to the stability in the first half of the period of observations.

Figure 2 shows distributions for the average CDS spread, corporate spread, absolute and relative liquidity premia: $56.8 \%$ of the daily CDS spread values are less than $0.5 \%$ (Figure 2 (a)); $44.1 \%$ of the daily corporate spread values lie between $0.5 \%$ and $1.0 \%$ (Figure 2 (b)); $83.5 \%$ of the daily values for the absolute liquidity premium are less than $1.0 \%$, of which $60.9 \%$ are less than $0.5 \%$ (Figure 2 (c)); and Figure 2 (d) shows an almost symmetrical and platykurtic distribution for the relative risk premium, for which around $61.4 \%$ of the daily observations are concentrated in the interval between $40 \%$ and $60 \%$.

Table 2 collates the statistical indicators for liquidity premium in absolute terms (unshaded) and relative terms (shaded) in each of the sub-periods previously described. As expected, the highest values for the mean absolute liquidity premium $(1.49 \%)$ and the greatest volatiilty as measured by the standard deviation $(0.43 \%)$ occur in the third period. By contrast, the lowest values are found in the first period, $0.22 \%$ and $0.06 \%$ for the mean and volatility respectively. In relative terms, the mean premium is similar in all four sub-periods, ranging from $40.2 \%$ in the first period to $46.4 \%$ in the fourth period. The first two periods show higher volatility, around $10.5 \%$, in contrast with the last period, whose standard deviation was $2.7 \%$.

Table 2

Descriptive Statistics: Liquidity Premium by Sub-period

\begin{tabular}{|c|c|c|c|c|c|}
\hline \multirow[b]{2}{*}{ Descriptive Statis ties } & \multicolumn{5}{|c|}{ Time frame of analys is } \\
\hline & $\begin{array}{l}11.01 .2005 \\
15.08 .2007\end{array}$ & $\begin{array}{l}16.08 .2007 \\
31.08 .2008\end{array}$ & $\begin{array}{l}01.09 .2008 \\
31.03 .2009\end{array}$ & $\begin{array}{l}01.04 .2009 \\
31.12 .2009\end{array}$ & Tothl \\
\hline Mean & $0.22 \% 40,2 \%$ & $0,51 \%, 42,5 \%$ & $1,49 \% \quad 43,5 \%$ & $0,9 8 \% \longdiv { 6 6 , 4 \% }$ & $0,54 \%, 42,0 \%$ \\
\hline Standard Error & $0,00 \%) 0,4 \%$ & $0,01 \% \quad 0,6 \%$ & $0,03 \% 0,6 \%$ & $0,02 \%, 0,2 \%$ & $0,01 \%, 0,3 \%$ \\
\hline Median & $0,23 \% \quad 37,6 \%$ & $0,53 \%, 43,6 \%$ & $1,45 \%, 42,7 \%$ & $0,82 \%, 462 \%$ & $0,29 \%, 44,5 \%$ \\
\hline Standard Deviation & $0,06 \% 10,4 \%$ & $0,12 \%, 10,5 \%$ & $0,43 \% 7,3 \%$ & $0,26 \% \sqrt{2,7 \%}$ & $0,47 \%, 6,6 \%$ \\
\hline Variance & $0.00 \% \quad 1,1 \%$ & $0,00 \%, 1,1 \%$ & $0,00 \%$ ए $0,5 \%$ & $0,00 \%, 0,1 \%$ & $0,00 \%, 0,9 \%$ \\
\hline Kurtosis & $-1,12=1,44$ & $0,80,1,14$ & $-0.12,0,07$ & $-0,81,0,023$ & $1,7500,38$ \\
\hline Skewness & $-0,36 \quad 0,02$ & $\begin{array}{ll}-0,74 \quad-0,84 \\
\end{array}$ & $.0,25,0,51$ & $0,750,07$ & $1,55 \quad-0,44$ \\
\hline Mininาum? & $0,07 \% \quad 17,8 \%$ & $0,13 \% \quad 8,3 \%$ & $0,52 \% 29,7 \%$ & $0,67 \% 39,7 \%$ & $0,07 \%$ \\
\hline Maxinzu!n & $0,32 \% \quad 59,0 \%$ & $0,76 \% \quad 62,3 \%$ & $2,33 \% \quad 64,1 \%$ & $1,55 \% \quad 52,9 \%$ & $2,33 \% \quad 64,1 \%$ \\
\hline Sum & 1275 & 1115 & $2 \quad 66$ & 2 & 7. 547 \\
\hline Count & $683 \quad 683$ & $272 \quad 272$ & $152 \quad 152$ & $197 \quad 197$ & $1.304 \quad 1304$ \\
\hline Conlidenec Interval (95,0\%) & $0,00 \% \quad 0,8 \%$ & $0,01 \%, \quad 1,3 \%$ & $0,07 \% \quad 1,2 \%$ & $0,04 \% \quad 0,4 \%$ & $0,03 \%$ \\
\hline
\end{tabular}

We also carried out an analysis of the evolution of the liquidity premium, in absolute and relative terms, for the different sectors (Figures 3, 4 and 5 and Table 3).

The results show that although the behaviour of each sector was similar, the impact of the financial crisis was greater on the liquidity premium in the automotive, TMT and consumer sectors. During the most volatile period, the absolute liquidity premium in these sectors rose above $3 \%$, which was more than double the mean for ail sectors for the same period.

140 
Figure 3

Evolution of the Liquidity Premium by Activity Sector

(a) Financial

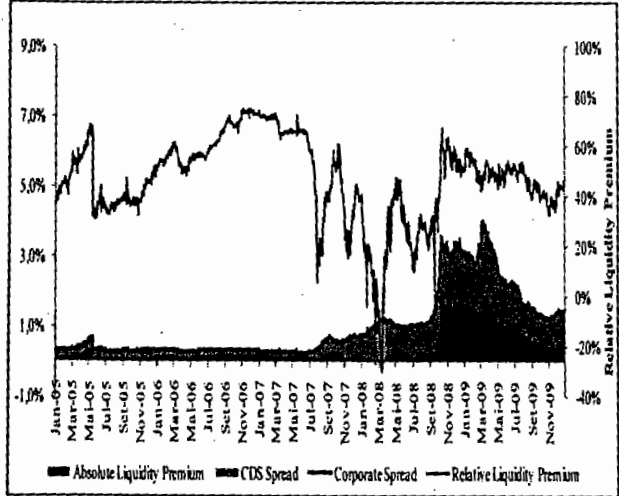

(c) Energetic

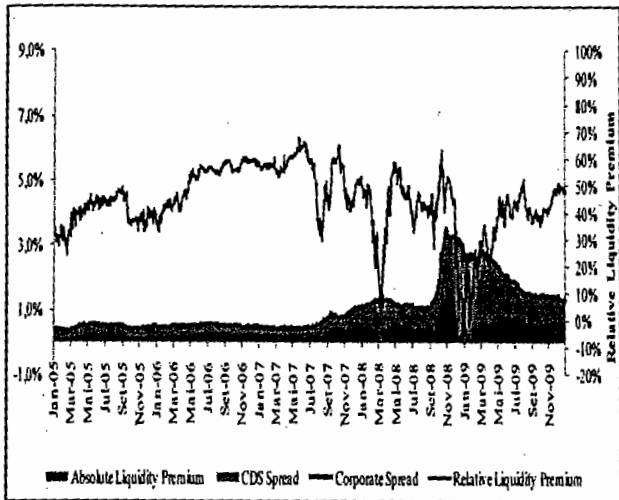

(e) TMT

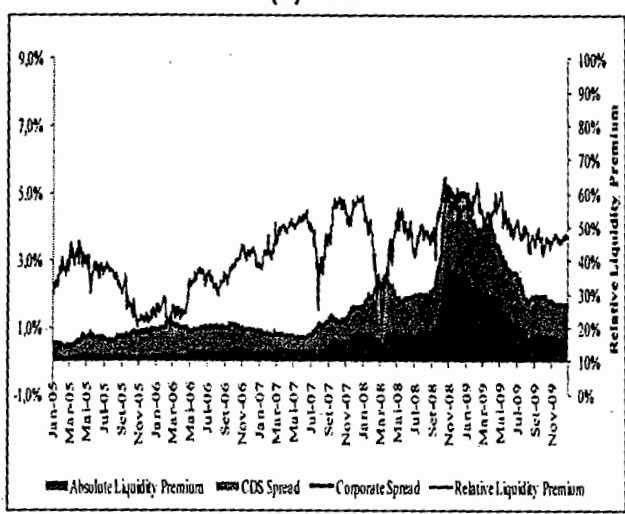

(b) Industrial

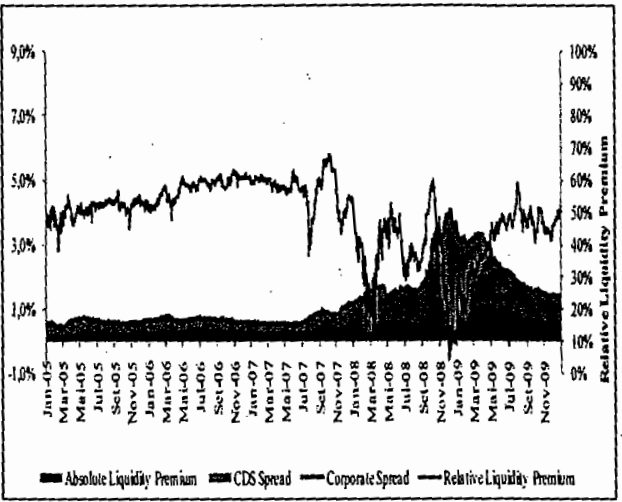

(d) Auto Manufacturers

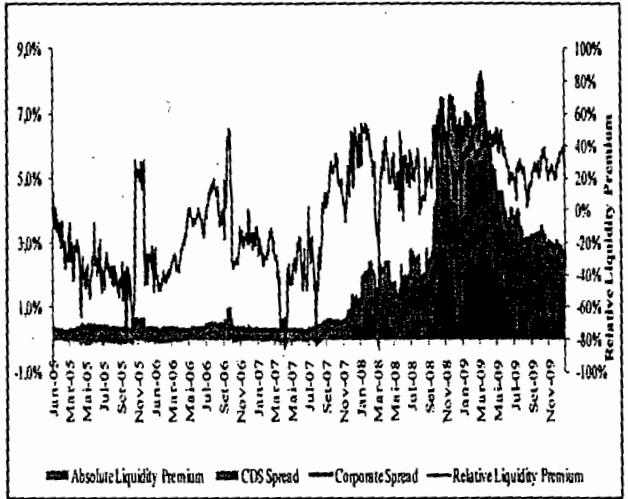

(f) Consumer

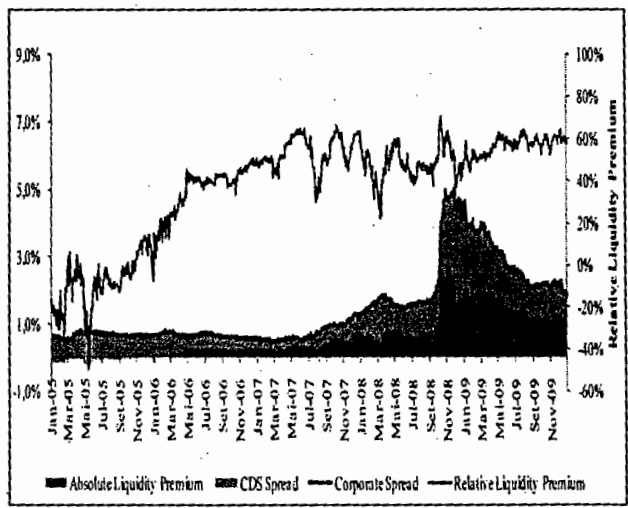

The absolute liquidity premium for the financial sector was generally lower than the mean for all sectors; it even registered some negative values in March 2008, as did the automotive sector.

This situation was due to a significant rise in the CDS premiums, but no 
corresponding rise in the corporate spread, thus confirming the idea that CDS spreads may, at least sometimes, reflect more than the credit risk of the reference entity and lead to underestimations of liquidity premia, particularly in stressed markets.

In relative terms the trends across the sectors were similar (Figures 3 and 5), with the exception of the negative values registered by the automotive and consumer sectors during the first two and a half years. These negative values were the result of the low values for CDS spreads and corporate bond yield spreads in relation to the liquidity premium. The higher values of the latter gave rise to a negative ratio, which was sometimes significant.

Figure 4

Liquidity Premium by sector, in absolute terms

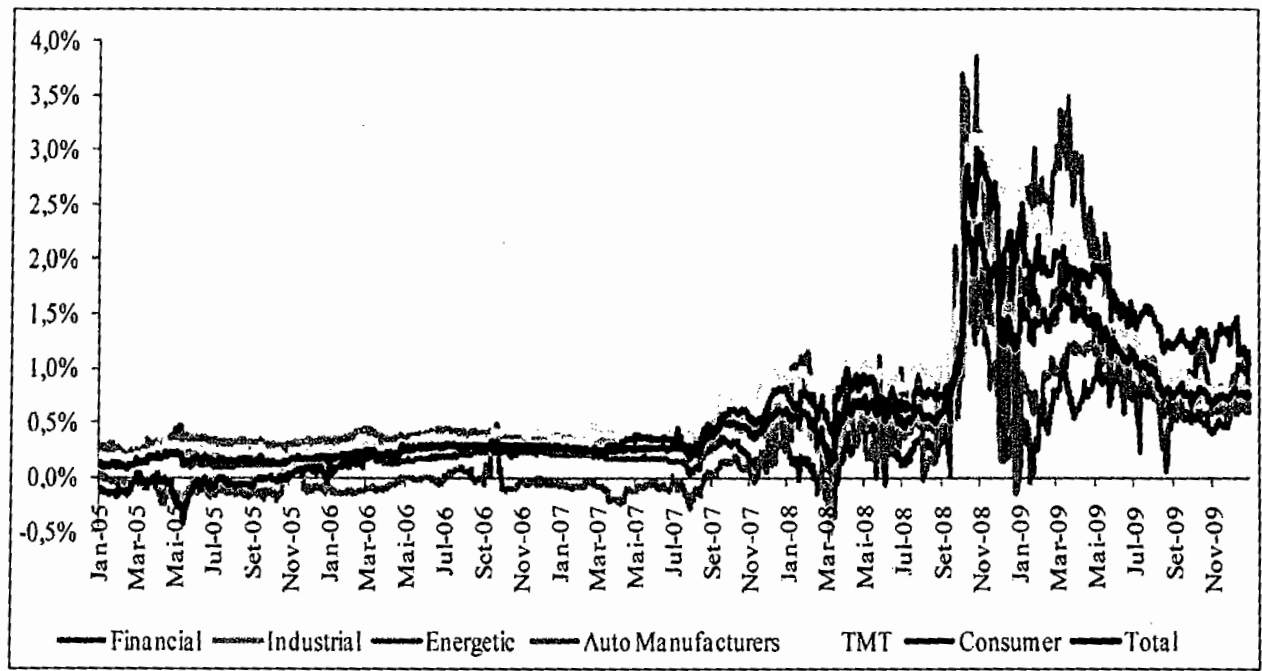

Figure 5

Liquidity Premium by sector, in relative terms

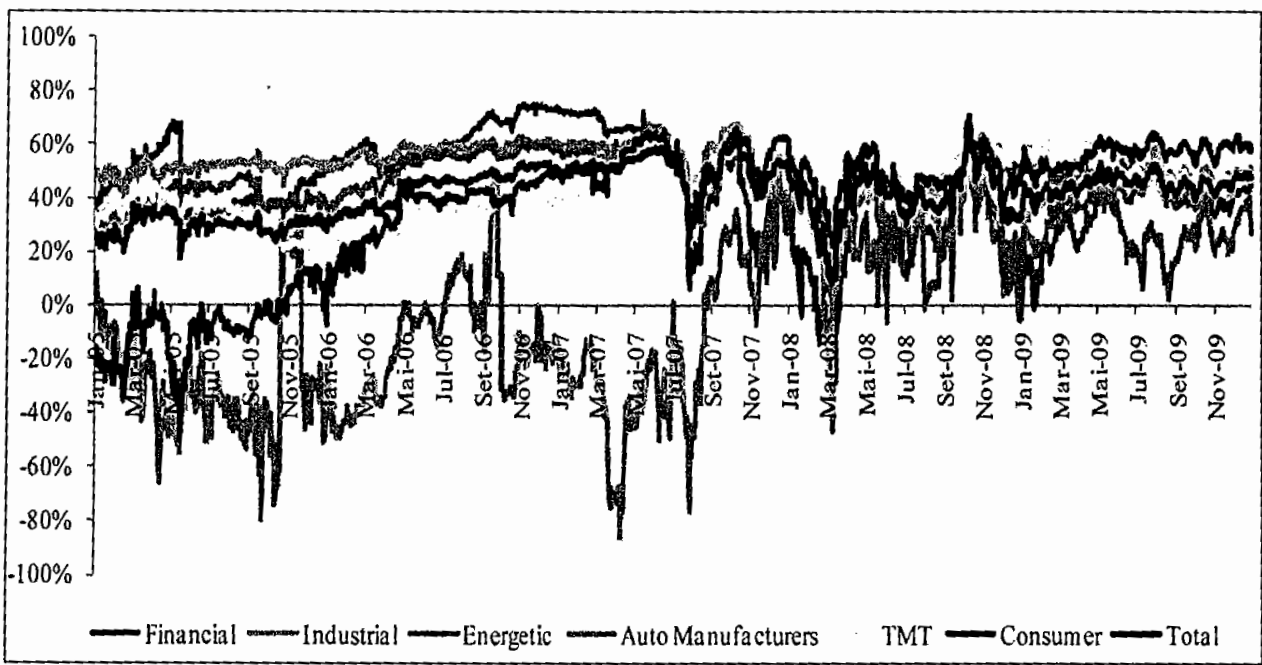

142 
Table 3 summarises the results for the liquidity premium in absolute (unshaded) and relative (shaded) terms for each sector for each sub-period. The TMT sector, at $0.78 \%$, shows the highest average absolute values for the whole period, soaring to $2.32 \%$ during the most volatile period. The consumer and industrial sectors also revealed absolute scores $(0.66 \%$ and $0.54 \%$ respectively) that were slightly above the total sector average of $0.54 \%$. In addition to recording the highest maximum absolute value, $3.85 \%$, the automotive sector also showed the greatest mean-standard deviation $(0.86 \%)$. While the absolute mean for the whole period was $0.46 \%$, it ranged from minus $0.7 \%$ in the first period to $2.16 \%$ in the crisis period. The financial and energy sectors show the lowest means for the absolute liquidity premium, $0.45 \%$ and $0.41 \%$ respectively. However, only the latter has the lowest standard deviation, $0.29 \%$, on a par with that of the industrial sector. In general, with the exception of the automotive sector, the absolute liquidity premium mean for all the sectors fell within a close range - between $0.14 \%$ in the consumer sector and $0.34 \%$ in the industrial sector - during the first, stable period up till August 2007. In the following period it rose significantly in

Table 3 (cont.)

Liquidity Premium by activity sector, in relative and absolute terms

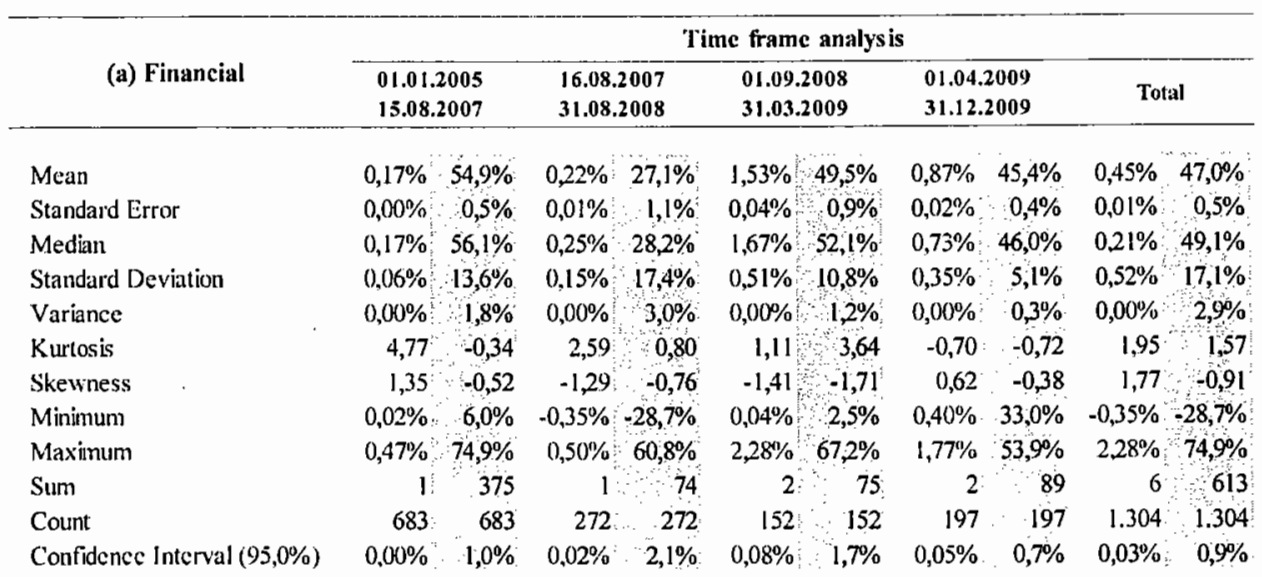

\begin{tabular}{|c|c|c|c|c|c|c|c|c|c|c|}
\hline \multirow[b]{2}{*}{ (b) Industrial } & \multicolumn{10}{|c|}{ Time frame analysis } \\
\hline & \multicolumn{2}{|c|}{$\begin{array}{l}01.01 .2005 \\
15.08 .2007\end{array}$} & \multicolumn{2}{|c|}{$\begin{array}{l}16.08 .2007 \\
31.08 .2008\end{array}$} & \multicolumn{2}{|c|}{$\begin{array}{l}01.09 .2008 \\
31.03 .2009\end{array}$} & \multicolumn{2}{|c|}{$\begin{array}{l}01.04 .2009 \\
31.12 .2009\end{array}$} & \multicolumn{2}{|c|}{ Total } \\
\hline Mean & $0,34 \%$ & $55,1 \%$ & $0,55 \%$ & $44,5 \%$ & $0,96 \%$ & $32,2 \%$ & $0,89 \%$ & $46,2 \%$ & $0,54 \%$ & $48,9 \%$ \\
\hline Standard Error & $0,00 \%$ & $0,2 \%$ & $0,01 \%$ & $0,8 \%$ & $0,03 \%$ & $1,1 \%$ & $0,01 \%$ & $0,3 \%$ & $0,01 \%$ & $0,3 \%$ \\
\hline Median & $0,34 \%$ & $55,4 \%$ & $0,55 \%$ & $44,5 \%$ & $0,95 \%$ & $31,6 \%$ & $0.85 \%$ & $46,4 \%$ & $0,41 \%$ & $51,4 \%$ \\
\hline Standard Deviation & $0,05 \%$ & $4,6 \%$ & $0,11 \%$ & $12,4 \%$ & $0,39 \%$ & $13,7 \%$ & $0,20 \%$ & $4,5 \%$ & $0,29 \%$ & $11,2 \%$ \\
\hline Variance & $0,00 \%$ & $0,2 \%$ & $0,00 \%$ & $1,5 \%$ & $0,00 \%$ & $1,9 \%$ & $0,00 \%$ & $0,2 \%$ & $0,00 \%$ & $1,3 \%$ \\
\hline Kurtosis & 0,64 & 0,05 & $0,73^{:}$ & $-0,45$ & $-0,22$ & $-0,64$ & $-1,43$ & 0,72 & 2,68 & 1,60 \\
\hline Skewness & $-0,39$ & $-0,60$ & $-0,42$ & $-0,09$ & 0,44 & 0,14 & 0,12 & 0,01 & 1,62 & $-1,26$ \\
\hline Minimum & $0.15 \%$ & $36,8 \%$ & $0,19 \%$ & $11,4 \%$ & $0,16 \%$ & $4,1 \%$ & $0,58 \%$ & $35,4 \%$ & $0,15 \%$ & $4,1 \%$ \\
\hline Maxinum & $0,45 \%$ & $62,9 \%$ & $0,81 \%$ & $67,7 \%$ & $1,88 \%$ & $60,2 \%$ & $1,25 \%$ & $59,0 \%$ & $1,88 \%$ & $67 ; 7 \%$ \\
\hline Sum & 2 & 376 & 1 & 121 & & 49 & 2 & $\therefore 91$ & 7 & 637 \\
\hline Count & 683 & 683 & 272 & 272 & 152 & 152 & 197 & $\therefore 197$ & 1.304 & 1,304 \\
\hline Confidence Interval $(95,0 \%)$ & $0,00 \%$ & $0,3 \%$ & $0,01 \%$ & $1,5 \%$ & $0,06 \%$ & $2,2 \%$ & $0,03 \%$ & $0,6 \%$ & $0,02 \%$ & $0,6 \%$ \\
\hline
\end{tabular}


Table 3 (cont.)

Liquidity Premium by activity sector, in relative and absolute terms

\begin{tabular}{|c|c|c|c|c|c|}
\hline \multirow[b]{2}{*}{ (c) Energetic } & \multicolumn{5}{|c|}{ Time frame analys is } \\
\hline & 01.01 .2005 & 16.08 .2007 & 01.09 .2008 & 01.04 .2009 & Total \\
\hline Mean & $0,23 \% \quad 48,5 \%$ & $0,46 \%, 44,6 \%$ & $0,78 \% \quad 30,4 \%$ & $0,70 \% \quad 41,5 \%$ & $0,41 \%, 44,5 \%$ \\
\hline Standard Error & $0,00 \%, 0,4 \%$ & $0,01 \%=0,7 \%$ & $0,04 \% 1,4 \%$ & $0,01 \% 0,4 \%$ & $0,01 \%=0,3 \%$ \\
\hline Median & $0,23 \% \quad 47,7 \%$ & $0,47 \% \quad 46,0 \%$ & $0,65 \%, 29,4 \%$ & $0,67 \%=41,5 \%$ & $0,29 \% 47 \%$ \\
\hline Standard Deviation & $0,05 \%, 98 \%$ & $0,12 \% 115 \%$ & $0,52 \% 17,0 \%$ & $0,12 \%, 6,0 \%$ & $0,29 \%$ W $12,2 \%$ \\
\hline Variance & $0,00 \% / 10 \%$ & $0,00 \% 13 \%$ & $0,00 \% 2,9 \%$ & $0,00 \%, 0,4 \%$ & $0,00 \% 15 \%$ \\
\hline Kurtosis & $-0,51 \% 1,16$ & 1,55 257 & $-0,83^{1,5} 1,06$ & $-0,431 \% 6$ & 5,62 俩 1,5 \\
\hline Skewness & $-0.57 \mathrm{~m} 021$ & $-0,86,134$ & $0,53,0,17$ & $0,60=0,88$ & 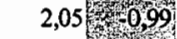 \\
\hline Minimum & $0,08 \% 24,4 \%$ & $0,04 \%, 2,8 \%$ & $-0,15 \%, 5,7 \%$ & $0,51 \% 21,1 \%$ & $-0,15 \%$ \% $5,2 \%$ \\
\hline Maxinum & $0,31 \% 67,7 \%$ & $0,69 \% 64,9 \%$ & $1,77 \% 63,0 \%$ & $1,06 \% 521 \%$ & $1,77 \% 67,7 \%$ \\
\hline Stun & 2331 & 1121 & 1,46 & 182 & 57580 \\
\hline Count & 683,683 & 272,272 & 152 ) 152 & 197197 & $1.304 \sqrt{1304}$ \\
\hline Confidence Interval $(95,0 \%)$ & $0,00 \% \quad 0,7 \%$ & $0,01 \% 14 \%$ & $0,08 \%, 27 \%$ & $0,02 \%, 0,8 \%$ & $0,02 \%=0,7 \%$ \\
\hline
\end{tabular}

\begin{tabular}{|c|c|c|c|c|c|}
\hline \multirow[b]{2}{*}{ (d) Auto Manufacture rs } & \multicolumn{5}{|c|}{ Time frame analysis } \\
\hline & $\begin{array}{l}01.01 .2005 \\
15.08 .2007\end{array}$ & $\begin{array}{l}16.08 .2007 \\
31.08 .2008\end{array}$ & $\begin{array}{l}01.09 .2008 \\
31.03 .2009\end{array}$ & $\begin{array}{l}01.04 .2009 \\
31.12 .2009\end{array}$ & Total \\
\hline Mean & $-0,07 \%=24,8 \%$ & $0,37 \%, 21,8 \%$ & $2,16 \%=34,2 \%$ & $1,12 \% 293 \%$ & $0,46 \% \quad 0,0 \%$ \\
\hline Standard Errol & $0,00 \% \quad 0,8 \%$ & $0,02 \%, 1,0 \%$ & $0,07 \%, 0,9 \%$ & $0,05 \%, 0,7 \%$ & $0,02 \%, 0,9 \%$ \\
\hline Median & $-0,09 \%-28,2 \%$ & $0,30 \%, 23,0 \%$ & $2,41 \% 36,1 \%$ & $0,89 \% \quad 27,0 \%$ & $0,02 \%, 35 \%$ \\
\hline Standard Deviation & $0,09 \% 22,1 \%$ & $0,36 \% 17,3 \%$ & $0,92 \%, \quad 10,9 \%$ & $0,65 \% 10,2 \%$ & $0,86 \% 32 \%$ \\
\hline Variance & $0,00 \% \quad 4,9 \%$ & $0,00 \%, 3,0 \%$ & $0,01 \% 12 \%$ & $0,00 \% 1,0 \%$ & $0,01 \% 10,4 \%$ \\
\hline Kurtosis & $8,86 \mathrm{~m}, 0,81$ & $-0,67,0,77$ & $-0,6500,34$ & 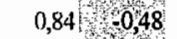 & 2,44 , 13 \\
\hline Skewness & $2,20 \mathrm{w} 0,54$ & $0,37,0,56$ & $-0,58,0,61$ & $1,31,0,13$ & $1,80 \times 0,21$ \\
\hline Mininum & $-0,28 \%-85,0 \%$ & $-0,67 \%, 47,4 \%$ & $-0,13 \% \% \quad 2,6 \%$ & $0,05 \% \quad 2,0 \%$ & $-0,67 \% 85,0 \%$ \\
\hline Maximum & $0,48 \% 50,3 \%$ & $1,14 \%, 53,1 \%$ & $3,85 \% 57,9 \%$ & $2,97 \%, 50,2 \%$ & $3,85 \% 57,9 \%$ \\
\hline Sum & 00170 & 1059 & 352 & 2558 & $6 x^{2} 0$ \\
\hline Count & $683 \quad 683$ & $272+272$ & $152 \% 152$ & $197^{10197}$ & $1.304 \quad 1304$ \\
\hline Confidence Interval $(95,0 \%)$ & $0,01 \% 1,7 \%$ & $0,04 \%, 2,1 \%$ & $0,15 \%, 1,7 \%$ & $0,09 \% 1,4 \%$ & $0,05 \%, 1 ; 8 \%$ \\
\hline
\end{tabular}

\begin{tabular}{|c|c|c|c|c|c|}
\hline \multirow[b]{2}{*}{ (c)TMT } & \multicolumn{5}{|c|}{ Time frame analysis } \\
\hline & $\begin{array}{l}01.01 .2005 \\
15.08 .2007\end{array}$ & $\begin{array}{l}16.08 .2007 \\
31.08 .2008\end{array}$ & $\begin{array}{l}01.09 .2008 \\
31.03 .2009\end{array}$ & $\begin{array}{l}01.04 .2009 \\
31.12 .2009\end{array}$ & Total \\
\hline Mean & $0,30 \%, 36,5 \%$ & $0,84 \%, 48,3 \%$ & $2,32 \%, 55,8 \%$ & $48,8 \%$ & $0,78 \%, 43,1 \%$ \\
\hline Standard Error & $0,00 \% 0,3 \%$ & $0,01 \% \quad 0,5 \%$ & $0,05 \%, 0,4 \%$ & $0,03 \% \quad 0,3 \%$ & $0,02 \% 0,0 \%$ \\
\hline Median & $0,30 \% \quad 37,0 \%$ & $0,90 \% \quad 49,1 \%$ & $2,42 \% \quad 56,0 \%$ & $0,91 \% \quad 47,6 \%$ & $0,42 \% 44,4 \%$ \\
\hline Standard Deviation & $0,08 \% \quad 8,5 \%$ & $0,14 \%, 7,9 \%$ & $0,58 \%, 4,4 \%$ & $0,43 \% \quad 4,1 \%$ & $0,70 \% 10,4 \%$ \\
\hline Variance & $0,00 \%, 0,7 \%$ & $0,00 \%, 0,6 \%$ & $0,00 \%, 0,2 \%$ & $0,00 \%$ & $0,00 \%$ \% $1,1 \%$ \\
\hline Kurtosis & $-1,28,0,71$ & $-0,22^{3} \quad 0,65$ & $0,12 \mathrm{~W}, 0,96$ & $-0,130,50$ & 2,07 \% 0,75 \\
\hline Skewness & $-0,04 \sqrt{0,02}$ & $-0,85 \quad 0,94$ & $-0,94 \sqrt{14} 0,67$ & $1,09,1,03$ & $1,69 \sqrt{1}, 0,31$ \\
\hline Minimım & $0,16 \% 20,4 \%$ & $0,40 \% 21,4 \%$ & $0,94 \%, 40,6 \%$ & $0,74 \% \quad 41,9 \%$ & $0,16 \%, 20,4 \%$ \\
\hline Maximum & $0,47 \% 54,7 \%$ & $1,05 \%, 59,3 \%$ & $3,12 \% 64,6 \%$ & $2,16 \% \quad 60,6 \%$ & $3,12 \% 64,6 \%$ \\
\hline Sum & 2250 & $2 \$ 131$ & $41 \times 85$ & $1+96$ & $10 \% 562$ \\
\hline Count & $683 \mathrm{k} 683$ & $272+272$ & 152152 & 197 , 197 & $1.304 \mathrm{~m} 1304$ \\
\hline Confidence Interval $(95,0 \%)$ & $0,01 \%, 0,6 \%$ & $0,02 \% \quad 0,9 \%$ & $0,09 \%, 0,7 \%$ & $0,06 \%, 0,6 \%$ & $0,04 \%, 0,6 \%$ \\
\hline
\end{tabular}

\section{4}


Table 3 (cont.)

Liquidity Premium by activity sector, in relative and absolute terms

\begin{tabular}{|c|c|c|c|c|c|c|c|c|}
\hline \multirow[b]{2}{*}{ (f) Consumer } & \multicolumn{8}{|c|}{ Time frame anulys is } \\
\hline & $\begin{array}{l}01.01 .2005 \\
15.08 .2007\end{array}$ & $\begin{array}{l}16.08 . \\
31.08\end{array}$ & 2007 & $\begin{array}{l}01.09 \\
31.03\end{array}$ & 2008 & $\begin{array}{l}01.04 \\
31.12\end{array}$ & $\begin{array}{l}2009 \\
2009\end{array}$ & Total \\
\hline Mean & $0,14 \%, \quad 22,9 \%$ & $0,68 \%$ & $49,9 \%$ & $1,95 \%$ & $50,9 \%$ & $1,45 \%$ & $58,5 \%$ & $0,66 \% \quad 37,2 \%$ \\
\hline Standard Error & $0,01 \% \quad 1,0 \%$ & $0,01 \%$ & $0,5 \%$ & $0,05 \%$ & $0,5 \%$ & $0,02 \%$ & $0 ; 2 \%$ & $0,02 \% \quad 0,7 \%$ \\
\hline Median & $0,21 \%, 32,4 \%$ & $0,68 \%$ & $49,3 \%$ & $1,96 \%$ & $50,8 \%$ & $1,38 \%$ & $58,8 \%$ & $0.35 \% \quad 46,4 \%$ \\
\hline Standard Deviation & $0,17 \%, 27,4 \%$ & $0,14 \%$ & $8,6 \%$ & $0,5 \% \%$ & $6,1 \%$ & $0,25 \%$ & $2,7 \%$ & $0,71 \%: 25,4 \%$ \\
\hline Variance & $0,00 \% \quad 7,5 \%$ & $0,00 \%$ & $0,7 \%$ & $0,00 \%$ & $0,4 \%$ & $0,00 \%$ & $0,1 \%$ & $0,00 \%, 6,4 \%$ \\
\hline Kultosis & $-0,82$ & $-0,53$ & 0,33 & $-0,28$ & 0,97 & $-0,80$ & $-0,30$ & $0,50 \quad 0,24$ \\
\hline Skewness & $-0,58 \quad-0,38$ & $-0,17$ & $-0,43$ & $-0,53$ & 0,56 & 0,62 & $-0,35$ & $1,12,-1,19$ \\
\hline Minimum & $-0,42 \%:-49,1 \%$ & $0,30 \%$ & $22,4 \%$ & $0,67 \%$ & $36,5 \%$ & $1,04 \%$ & $51,1 \%$ & $-0.42 \%-49,1 \%$ \\
\hline Maximum & $0,44 \% \quad 64,9 \%$ & $0,98 \%$ & $65,9 \%$ & $3,01 \%$ & $70,9 \%$ & $1,95 \%$ & $64,1 \%$ & $3,01 \% \quad 70,9 \%$ \\
\hline Sum & $1 \quad 156$ & 2 & 136 & 3 & 77 & 3 & 115 & $9 \quad 485$ \\
\hline Count & $683 \quad 683$ & 272 & 272 & 152 & 152 & 197 & 197 & $1.304 \quad 1,304$ \\
\hline Confidence Interval $(95,0 \%)$ & $0,01 \%$ & $0,02 \%$ & $1,0 \%$ & $0,10 \%$ & $1,0 \%$ & $0,04 \%$ & $0,4 \%$ & $0,04 \% \quad 1,4 \%$ \\
\hline
\end{tabular}

all sectors except for the financial, in which it essentially remained unchanged. In the third period, however, the liquidity premium mean for the financial sector showed the greatest percentage increase, rising almost sixfold.

\subsection{ROBUSTNESS TESTS}

As noted earlier, one of the problems inherent in the method of exact matching between CDS and their underlying bonds stems from potential differences in the maturities of the CDS and the underlying bonds. In fact, as shown in Figure 6, the average maturity for the bonds underlying the CDS revealed a declining trend, ranging from a maximum of 6.8 to a minimum of 4.6 years while CDS were always held to have a maturity of 5 years.

Figure 6

Average Maturity of reference assets for 5 year CDS contracts

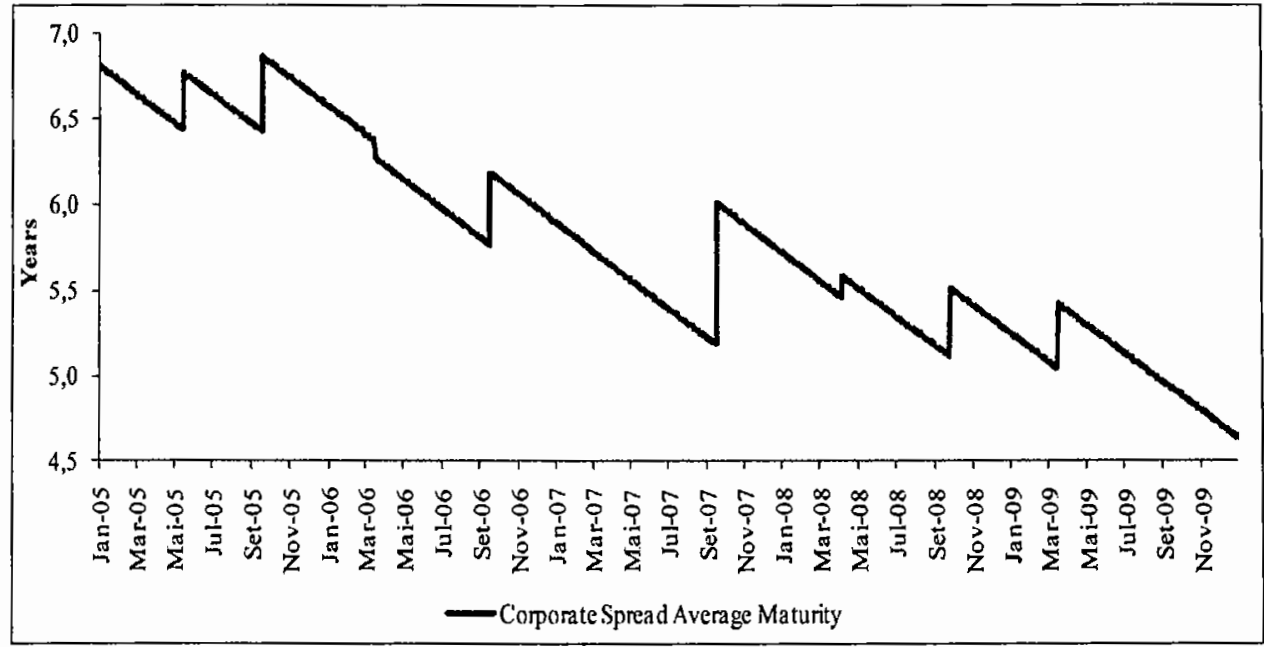


In order to test the robustness of the results we applied the naive method described in section 3.1, which computes liquidity premia simply by using CDS and bond indices. For this robustness check we used only series 2 of the 5-year CDS Markit iTraxx Europe index, as a proxy for the CDS spread, and to proxy the corporate spread we used the yield of a bond index that we built and which will be referred to as the "Markit iBoxx Euro Corporates 5" index. This index is derived from a weighted average of the Markit iBoxx Euro Corporates 3-5 and the Markit iBoxx Euro Corporates 5-7. The index was weighted according to the respective daily value of each index. The purpose of creating a new index resulted from the need that the constituents of the bond index should be as close as possible to the reference bonds underlying the CDS contracts in the 5-year CDS Markit iTraxx Europe index with regard to the rating, seniority and maturity.

Table 4 compares our "Markit iBoxx Euro Corporates 5" with the existing Markit iBoxx market indices. At the end of the period under study, on 31 December 2009, all three indices had an average rating of $A$. It should be noted that one of the criteria for inclusion in iBoxx indices that an asset have investment grade status, as is the case for inclusion in CDS iTraxx indices. Although the iBoxx indices are not made up exclusively of senior debt, as is the case of the bonds underlyings of the CDS in iTraxx indices, the percentage of subordinate debt, at our Markit iBoxx Euro Corporates 5, is very low: $13.1 \%$. With regard to maturity, the maturities of the constituents in our Markit iBoxx Euro Corporates 5 index fluctuated between 4.6 and 5.1 years. The average maturity was 4.8 years, which is relative close to the CDS Markit iTraxx Europe index maturity of 5 years. We compare the evolution of the average maturity of the bonds in Markit iBoxx Euro Corporates 5 index (Figure 7) and that of reference bonds for the CDS constituents of the 5-year CDS Markit iTraxx Europe index (Figure 6). Finally, Table 5 compares the distributions per sector of the constituent bonds of the iBoxx indices. The Markit iBoxx Euro Corporates 5 has a large exposure to the financial sector $(41.1 \%)$, followed by the utilities $(13.3 \%)$, telecommunications $(9.0 \%)$, industrial $(8.6 \%)$, and consumer goods $(8.6 \%)$.

Table 4

iBoxx Index Indicators, 31 December 2009

\begin{tabular}{lccc}
\multicolumn{1}{c}{ Data } & $\begin{array}{c}\text { Markit iBoxx } € \\
\text { Corporates 3-5 }\end{array}$ & $\begin{array}{c}\text { Markit iBoxx } € \\
\text { Corporates 5-7 }\end{array}$ & $\begin{array}{c}\text { Markit iBoxx } € \\
\text { Corporates 5 }\end{array}$ \\
\hline Index Level (Price Return) & 93,15 & 92,30 & 92,87 \\
Index Level (Total Return) & $161 ., 54$ & 161,82 & 161,63 \\
Market Value (10 ${ }^{6}$ euros) & 441.717 & 224.605 & 666.322 \\
Nominal Value (10 euros) & 409.087 & 214.660 & 623.746 \\
Annual Yield (\%) & $3,82 \%$ & $4,68 \%$ & $4,11 \%$ \\
Annual Modified Duration (years) & 3,38 & 4,88 & 3,89 \\
Average Maturity (years) & 3,88 & 5,92 & 4,57 \\
Average Rating & $\mathrm{A}$ & $\mathrm{A}$ & $\mathrm{A}$ \\
Senior Debt (\%) & $88,9 \%$ & $83,1 \%$ & $86,9 \%$ \\
Assets Nunber & 409 & 234 & 643 \\
\hline
\end{tabular}


Figure 7

Evolution of the maturity of the Markit iBoxx Euro Corporates 5 Index

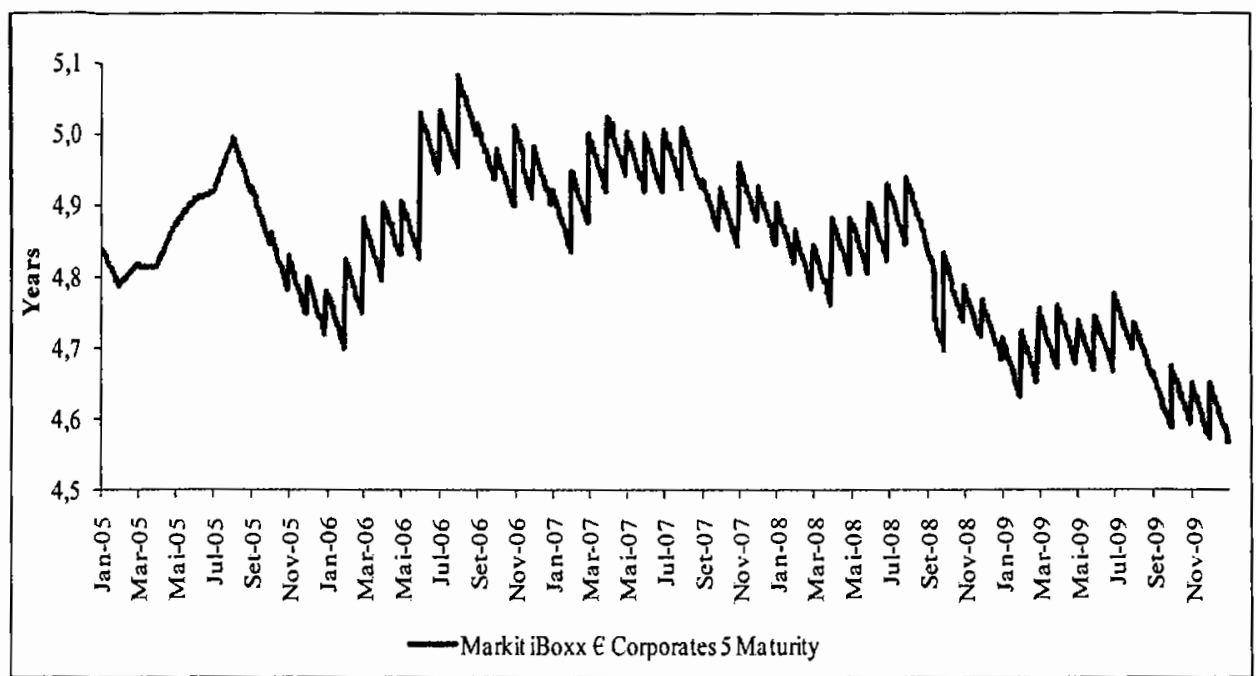

Table 5

Bond Index Indicators

\begin{tabular}{|c|c|c|c|c|c|c|}
\hline \multirow{2}{*}{ Sector } & \multicolumn{2}{|c|}{ iBoxx E Corporates 3-5 } & \multicolumn{2}{|c|}{ iBoxx $\in$ Corporates 5-7 } & \multicolumn{2}{|c|}{ iBoxx $\in$ Corporates 5} \\
\hline & $\mathbf{N}^{\circ}$ Assets & $\%$ & $\mathbf{N}^{0}$ Assets & $\%$ & $N^{\circ}$ Assets & $\%$ \\
\hline Financial & 176 & $47,0 \%$ & 92 & $35,4 \%$ & 268 & $43,1 \%$ \\
\hline Uilinies & 52 & $11,3 \%$ & 39 & $17,2 \%$ & 91 & $13,3 \%$ \\
\hline Telecommunications & 35 & $8,4 \%$ & 21 & $10,1 \%$ & 56 & $9,0 \%$ \\
\hline Industcial & 41 & $8,4 \%$ & 23 & $9,2 \%$ & 64 & $8,6 \%$ \\
\hline Consumer Goods & 37 & $8,8 \%$ & 17 & $8,2 \%$ & 54 & $8,6 \%$ \\
\hline Basic Materials & 17 & $3,5 \%$ & 15 & $6,0 \%$ & 32 & $4,4 \%$ \\
\hline Consumer Sevices & 23 & $4,1 \%$ & 12 & $4,7 \%$ & 35 & $4,3 \%$ \\
\hline Health Care & 8 & $3,5 \%$ & 8 & $5,6 \%$ & 16 & $4,2 \%$ \\
\hline Energy & 17 & $4,2 \%$ & 7 & $3,5 \%$ & 24 & $4,0 \%$ \\
\hline Technology & 3 & $0.7 \%$ & 0 & $0,0 \%$ & 3 & $0.4 \%$ \\
\hline
\end{tabular}

Figure 8 shows the evolutions of the CDS index spread, the corporate spread (computed from the difference between the yield of the Markit iBoxx Euro Corporates 5 index and treasury bonds) and of the liquidity premium (in absolute and relative terms). It is clear that the trends shown over the 5 years are similar to those previously obtained (compare Figures 1 and 8 ). In fact, there is a strong positive global correlation of 0.92 between absolute liquidity premia obtained by the matching and naive methods. This confers robustness the results of Section 3.2.

Nevertheless, as shown by Figure 9, the two approaches do give rise to different magnitudes for the liquidity premium during certain periods, namely between August 2007 and November 2008. As we have seen, this period coincides with an increase in the value of the liquidity premium. Using direct matching between the CDS and the 
Figure 8

Evolution of the Liquidity Premium: Index Methodology

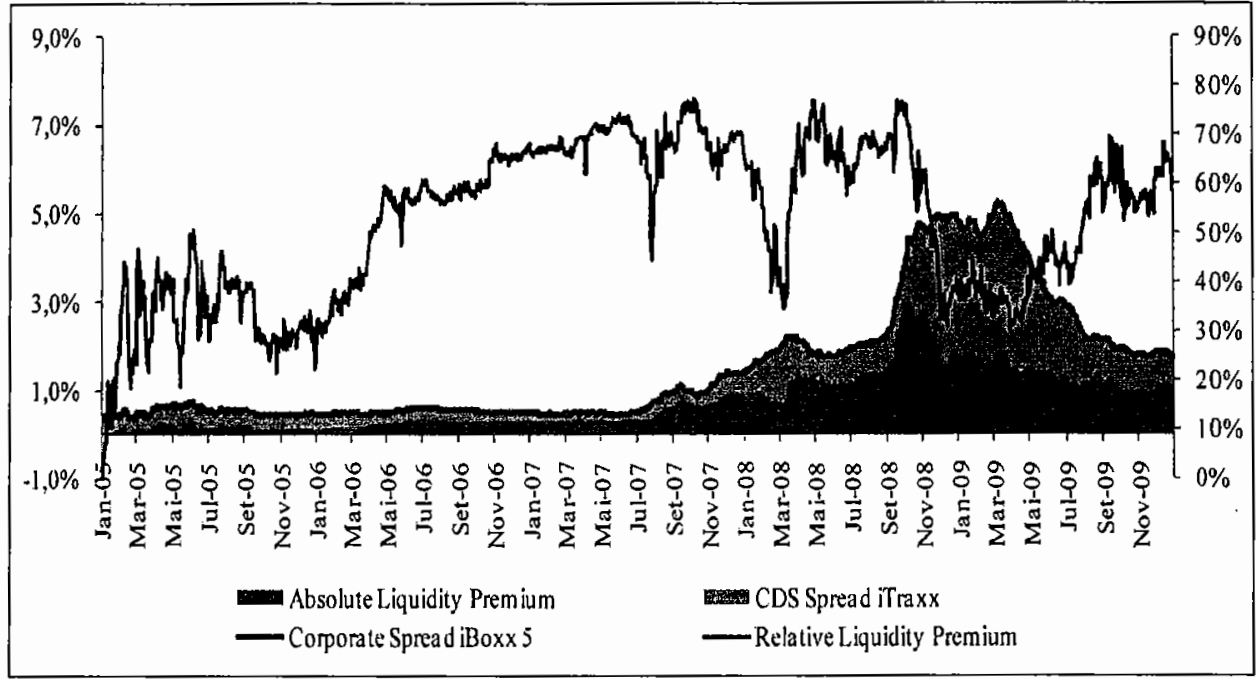

Figure 9

Absolute Liquidity Premium: Comparison of Methodologies

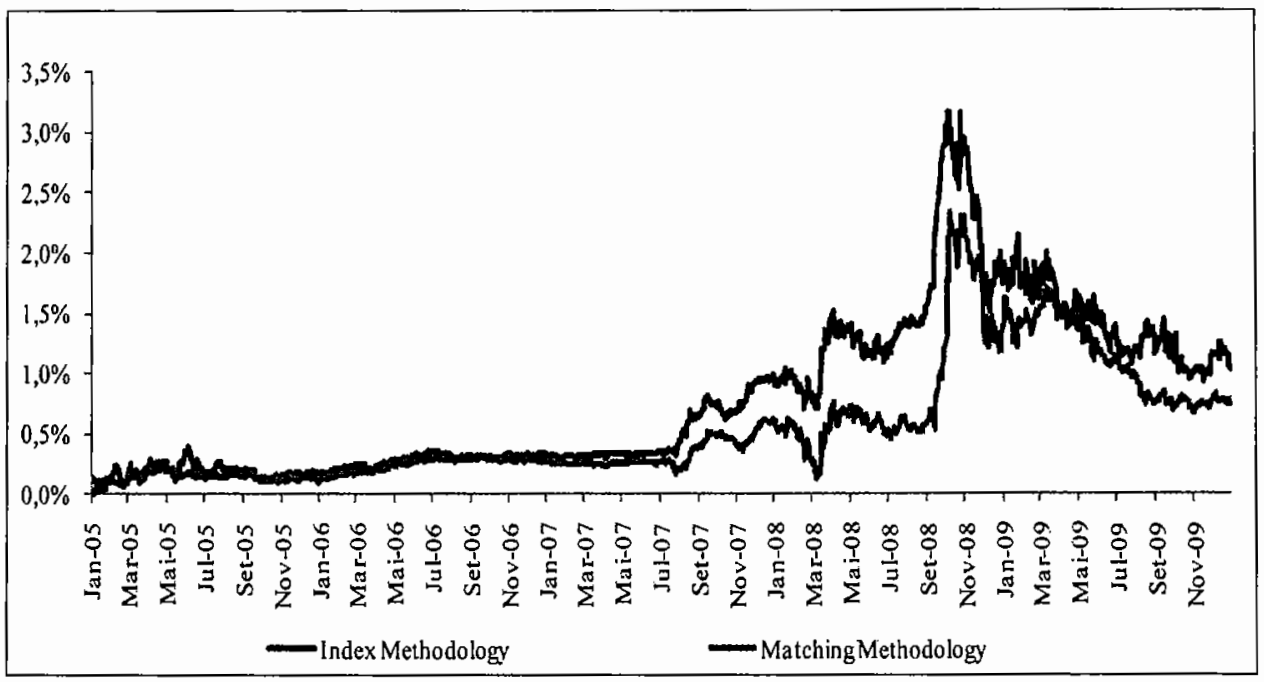

corporate bonds, the values for the liquidity premium were lower and the difference increased to a maximum of $1.7 \%$ at the peak of the crisis at the end of September 2008.

Figure 10 shows that the values estimated by the matching and naive methods for relative liquidity premia also foliow similar trends, although the naive method generated higher values over the crisis period. The two relative risk premium series have a positive correlation of 0.74 .

Despite the strong correlation and similarity between the evolutions of the liquidity premia over time in the two methods, the differences confirm the idea that computing 148 
Figure 10

Relative Liquidity Premium: Comparison of Methodologies

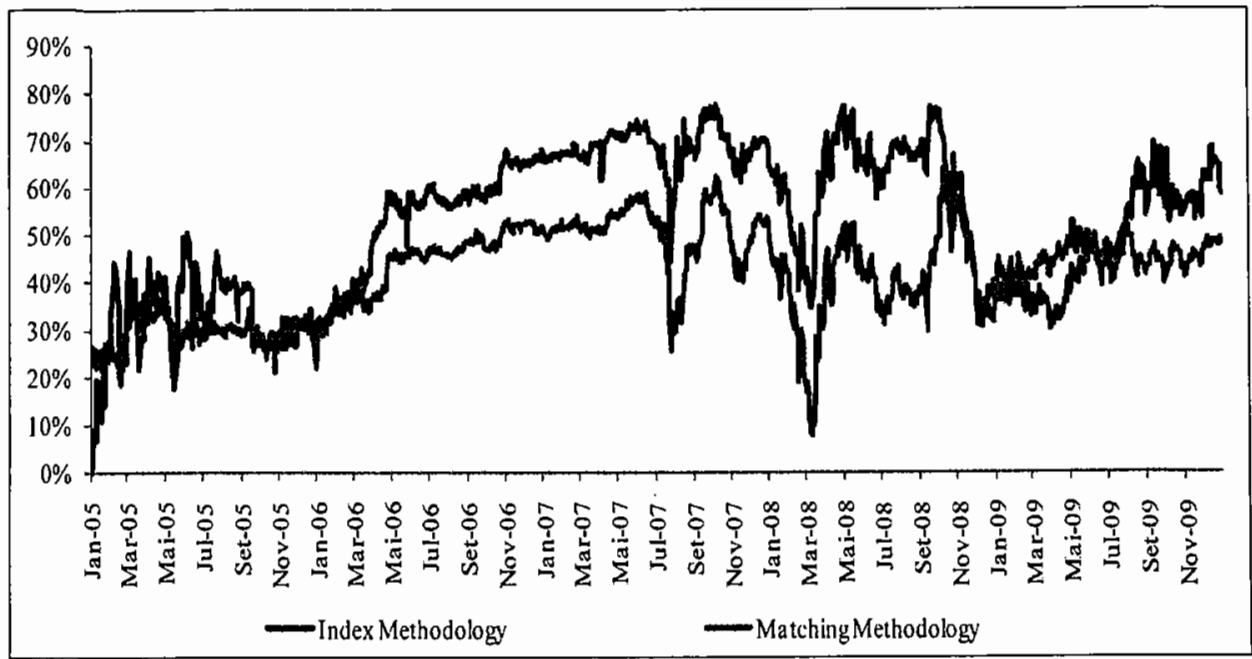

the liquidity premium is very sensitive to the assumptions and the information used to do so, and this hinders the comparison of results from studies using different methodologies.

To conclude the robustness analysis, it must be noted that if we had opted to use 5 -year swap rates instead of treasury bond yields as a proxy for the risk-free assets, the daily liquidity premium obtained would be lower, since, in the period under analysis, the Euro Benchmark yield curve is, on average, about $0.4 \%$ higher than that of the 5 -year swap rate, and in the periods in which the negative effects of the financial crisis were most apparent, this difference grows to $0.9 \%$, in other words, more than double the average observed. See Figure 11.

Figure 11

Euro Benchmark Curve and 5-year Swap Rate Yields

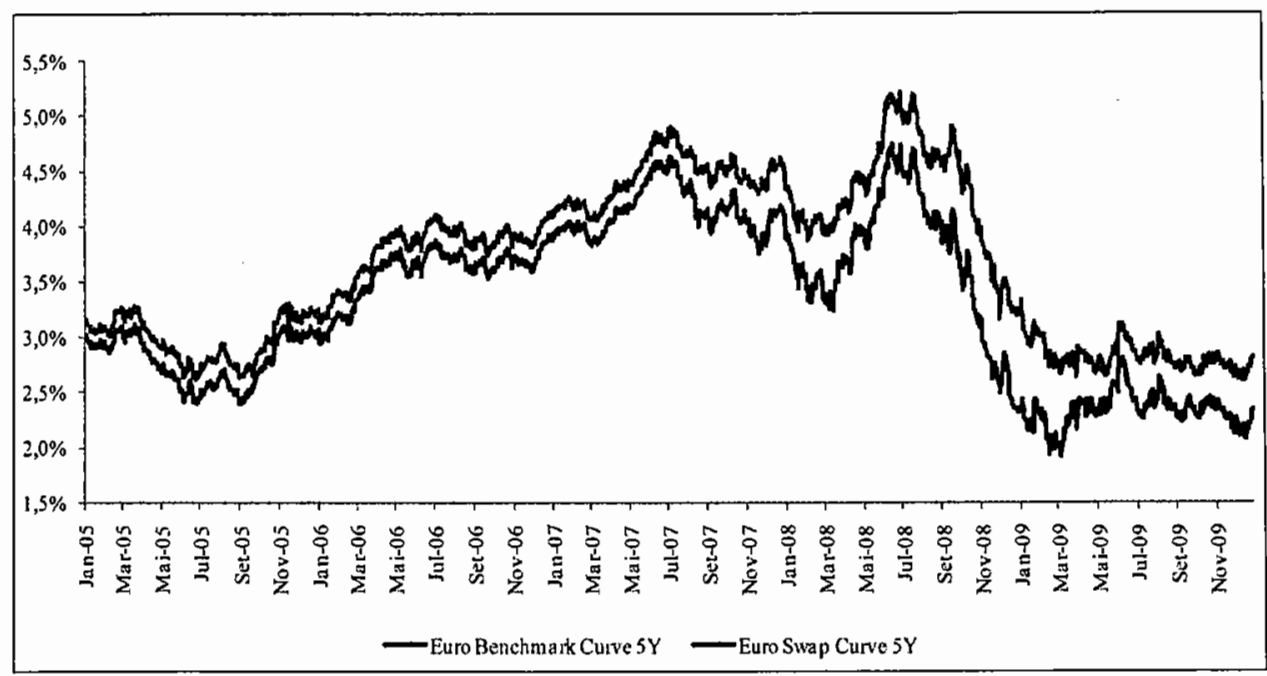




\section{CONCLUSIONS}

The main aim of this study was to clearly illustrate the impact of liquidity risk, especially during the subprime crisis, thus demonstrating the need to consider an additional liquidity premium in discount rates used in mark-to-model valuation of illiquid financial assets. The average liquidity premium for European corporate bonds, as estimated by the Longstaff et al. (2005) methodology, was $0.54 \%$ during the period between January 2005 and 2010 , which represented $42.0 \%$ of the corporate spread yield. The results showed that the liquidity premium fluctuated during the period, reaching significant values during crisis periods, and these results are in line with previous studies.

Our results were obtained by a direct matching CDS contracts with their underlying reference bonds, comparing the CDS spread with the yield spread of the reference bond. Although this methodology is not trouble-free and requires more complicated computations, it is nonetheless theoretically sounder than merely comparing index CDS spreads with yield spreads of corporate bond indices. Moreover, because it requires the liquidity premium to be computed bond by bond, it enables a more detailed analysis. In this study, we were able to analyse liquidity premia by sector of activity, which is unusual in the literature. The analysis by sector showed that the impact of the recent financial crisis was greater on the liquidity premia of bonds whose issuers were from the automotive, TMT and consumer sectors; the liquidity premiums for these sectors were double the global average. By contrast, that of the financial sector was almost always below the global average, which may seem puzzling bearing in mind that the financial sector was at the core of the recent crisis. Moreover, both in the financial and automotive sectors our results showed some temporary negative values for liquidity risk premia. Some of the "anomalies" in our results can be explained by the significant increase in CDS premiums, more evident in some sectors than others, during the periods of stressed markets. An increase in CDS spreads not accompanied by an increase in yield spreads of the underlying reference bond acts as a warning that the CDS spread can include risks other than credit risk of the reference bond issuer. The lack of confidence in the markets that was shown during the recent financial crisis suggests that, during that period, possibly a considerable portion of the CDS spreads reflected counterparty risk or the liquidity risk of the CDS markets (due to the OTC nature of these contracts and the uncertainty regarding physical settlement of some contracts). The recent establishment of Central Counterparties Clearing Houses and the greater regulation of the CDS settlement processes (creating auctions and making the financial settlement of CDS contracts the rule rather than the exception), probably helped to eliminate these other risks of CDS contracts. How much of CDS spreads can actually be attributed to risks other than the credit risk of its reference entity is, without question, an interesting open question for future research. As far as our results are concerned, because the initial period covered by this study was prior to the establishment of these confidence-inducing mechanisms, it is highly likely that the estimations of the liquidity risk premiums for this period are undervalued. This result merely reinforces the importance of liquidity risk.

150 


\section{REFERENCES}

Amihud Y. (2002), Illiquidity and stock returns: cross-section and time-series effects, Journal of Financial Markets, 5, p.p. 31-56.

Amihud Y. e Mendelson H. (1986), Asset pricing and the bid-ask spread, Journal of Financial Economics, 17, p.p. 223-249.

Bao, J., Pan, J., and Wang, J. (2009), Liquidity of corporate bonds, Working paper.

Bongaerts, D., De Jong, F. and Driessen, J. (2008), Liquidity and liquidity risk premia in the CDS market, Working paper, University of Amsterdam.

Chen, R., X. Cheng, and L. Wu (2005), Dynamic Interactions Between Interest Rate, Credit, and Liquidity Risks: Theory and Evidence from the TermStructure of Credit Default Swap Spreads, Working Paper.

Chen, L., Lesmond, D. A. and Z., W. J. (2007), Corporate yield spreads and bond liquidity, Journal of Finance, 62, p.p. 119-149.

Collin-Dufresne, Goldstein, and Martin (2001). The Determinants of Credit Spread Changes, Journal of Finance, 56, p.p. 2177-2207.

Cremers, M., Driessen, J., Maenhout, P. and Weinbaum, D. (2004), Individual stock-option prices and credit spreads, Working paper, Yale ICF.

De Jong, F. and Driessen, J. (2005), Liquidity risk premia in corporate bond markets, Working paper, University of Amsterdam.

Dick-Nielsen, J., Feldhütter, P. and Lando, D. (2009), Corporate bond liquidity before and after the onset of the subprime crisis, Working paper.

Dignan, J. (2003), Nondefault components of investment-grade bond spreads, Financial Analysts Journal, May/June: p.p. 93-102.

Duffie, D. (1999), Credit swap valuation, Financial Analysts Journal, 55, p.p. 73-87.

Duffie, D. and Liou, J. (2001), Floating-fixed credit spreads, Financial Analysts Journal, 57 , p.p. $76-87$.

Duffie, D. and Singleton, K. (2003), Credit Risk: Pricing, Measurement and Management, Princeton University Press, Princeton.

Ericsson, J., Reneby, J. and Wang, H. (2005). Can structural models price default risk? Evidence from bond and credit derivative markets. Working paper, EFA 2005 Moscow Meetings.

Houweling, P., Mentinck, A. and Vorst, T. (2005). Comparing possible proxies of corporate bond liquidity. Journal of Banking and Finance, 29, p.p. 1331-1358.

Kyle A. (1985). Continuous auctions and insider trading. Econometrica, 53, p.p. $1315-1335$.

Lesmond, D., Ogden J. and Trzcinka C. (1999), A new estimate of transaction costs, Review of Financial Studies, 12, p.p. 1113-1141.

Longstaff, F., Mithal, S. and Neis, E. (2005). Corporate yield spreads: Default risk or liquidity? New evidence from the credit default swap market. Journal of Finance, 60, p.p.2213-2253.

Martellini, L., Priaulet, P. and Priaulet, S. (2006), Fixed Income Securities: Valuation, Risk Management and Portfolio Strategies, Wiley Finance.

Merton, R. (1974), On the pricing of corporate debt: The risk structure of interest rates. Journal of Finance, 29 , p.p. 449-470.

Roll, R. (1984). A simple implicit measure of the effective bid-ask spread in an efficient market. Journal of Finance, 39, p.p. 1127-1139.

Tang, D. and H. Yan (2006), Liquidity, Liquidity Spillover, and Credit Default Swap Spreads, Working Paper.

Webber, L. (2007), Decomposing corporate bond spreads, Bank of England Quarterly Bulletin 
